\title{
Erratum to: Subacute painful thyroiditis accompanied by scrub typhus infection
}

\author{
Sun hee Kim • Tae Sun Park • Hong Sun Baek •
}

Heung Yong Jin

Published online: 25 April 2013

(c) Springer Science+Business Media New York 2013

\section{Erratum to: Endocrine}

\section{DOI 10.1007/s12020-013-9947-5}

In the original publication, the given name of the first author is incorrectly captured. The correct name is Sun hee Kim.

The online version of the original article can be found under doi: 10.1007/s12020-013-9947-5.

S. h. Kim · T. S. Park · H. S. Baek · H. Y. Jin $(\varangle)$

Division of Endocrinology and Metabolism, Department

of Internal Medicine, Research Institute of Clinical Medicine of Chonbuk National University, Chonbuk National University

Hospital, Chonbuk National University Medical School, 634-18, Keum-Am Dong, Jeonju 561-712, South Korea

e-mail: mdjinhy@jbnu.ac.kr 